\title{
STAGED IMPROVEMENT OF DELIVERY-ORIENTED PRODUCTION
}

\author{
Ho, Y.-L. \\ Department of Wealth Management, Hsing Wu University \\ No. 101, Sec. 1, Fenliao Rd., LinKou District, New Taipei City 24452, Taiwan (R.O.C.) \\ E-Mail: 096063@mail.hwu.edu.tw, elaineho614@gmail.com
}

\begin{abstract}
This study proposes a system dynamics (SD) model to deal with the staged improvement of delivery-orientated production plan. The situations, such as the cycle time affected by total input of human resource, unit transportation cost influenced by amount of delivery quantity, unit penalty (shortage) cost affected by amount of shortages, and the time delay among customer demand, production demand, order quantity, material demand, and inventory are discussed. A dynamic approach to adjusting enterprise's policy for conforming customers' satisfactions is a practical problem, but past studies lack discussions. Therefore, this work aims to construct a dynamic approach for conforming the customers' satisfactions. Research results reveal that the increment of production capacity and replenishment material policy could lead the shortage reduction, but do not achieve the complete improvement "none shortage". Decreasing the affection of time delay would bring the production reaching the complete improvement.

(Received in November 2013, accepted in August 2014. This paper was with the author 1 month for 1 revision.)
\end{abstract}

Key Words: Delivery-Oriented, System Dynamics, Improvement, Shortage

\section{INTRODUCTION}

System thinking is a qualitative process, and its quantitative process is simulation. Systems thinking has its origins in biology, but it has been widely applied in different scientific disciplines, from medicine and engineering to psychology, from economics and business management to art, and so on [1-8]. Schiuma et al. (2012) described that systems thinking is a powerful approach to understand the "reality system" that emphasizes the relationships among the system's parts rather than the parts themselves [9]. Yim et al. (2004) proposed that system dynamics is suggested to be a simulation method of knowledge-based decision-making [10]. Larsen et al. (1997) stated that simulation is generally thought of as a tool for forecasting and prediction [11]. Simulation was primarily used to forecast a variety of complex systems and it is also used as a tool to help a team of managers understand the company's problems and opportunities, both current and future [11].

System dynamics (SD) is used as a modelling tool because of its rigorous approach in capturing interrelationships among variables and in handling dynamic aspects of the system behaviour [12]. SD, initially developed by Forrester (1961), is a method for qualitative description and analysis of complex systems and quantitative simulation of system behaviour. Currently, SD has been applied in many diverse areas from software development, strategic planning to project management [13-17]. SD could be divided into two stages, qualitative and quantitative analysis. Tako and Robinson (2012) described that a widely held belief exists which SD is mostly used to model problems at a strategic level [18]. Suryani et al. (2010 a, $2010 \mathrm{~b}$ ) described that the main characteristics of SD are the existence of complex system, the change of system behaviour from time to time and also the existence of the closed loop feedback [19-20]. They mentioned that system dynamics is used to model and to generate scenarios for forecasting demand and evaluating policy scenarios, which will enable us to understand the nonlinear dynamics behaviour in uncertain conditions [19-20]. 
Based on the above-mentioned reasons, the system simulation would be the better method for system behaviour prediction. Several applications of SD model, such as, Quaddus and Intrapairot (2001) developed a system dynamics (SD)-based decision support system (DSS) to analyse the management policies on the diffusion of data warehouse (DW) in a large commercial bank in Thailand [12]. Lyneis (2000) has developed system dynamics model to forecast demand of commercial jet aircraft industry [21]. While the demand for air travel is difficult to forecast, it is important to utilize system dynamics [21]. James and Galvin (2002) have utilized system dynamics to determine the future behaviour of the principle components of the air traffic control (ATC) system over time [19]. In addition, Li et al. (2012) proposed a SD model to simulate the management process of the power grid engineering project [22]. Larsen et al. (1997) stated that system dynamics can help understand a service company's growth potential as well as its limitations [11]. Xu and $\mathrm{Li}$ (2011) developed a system dynamics model with fuzzy multiple objective programming (SD-FMOP). This model can be used to study the complex interactions in an industry system [23].

The total cost of production should consider some aspects, such as holding and penalty costs [24]. Traditionally, the cost of holding inventory is assumed linearly increasing with a rate that is equal to a percentage of the product value [25-26]. In addition, Liu and Li (2006), Kosuch and Lisser (2010), and Estevez-Fernandez (2012) all discussed the penalty cost in their studies [27-29]. In addition, the production yield is regarded as an important factor in production planning because a better production yield would catch the less cost loss [30-33]. Delivery on time is an important issue, and meeting due dates is the most important goal of scheduling since the due date of each job has been promised to the customer [34]. If an enterprise does not comply with the order deadline to satisfy the customer need, it will decrease its competitive advantage and will lose its market share. So, meeting the delivery deadline of contract is very important.

Performance analysis is a concurrent important topic [35]. Schiuma et al. (2012) apply a systems thinking framework to assess knowledge assets dynamics for business performance improvement [9]. Cannon (2008) discusses the robustness of inventory improvement as an indicator of overall financial performance [36]. Xu (2012) states that there are many advantages to analysing performance at the design level, rather than waiting until system testing [37]. Aburas (2010) recognizes that evaluating corporate performance of a multi-business company is complicate. It should be viewed from various perspectives, and has to satisfy multiple objectives [38].

Based on those works mentioned previously, they reveal that a dynamic approach for adjusting enterprise's policy to conform the customers' satisfactions is seldom discussed. Therefore, this paper tries to construct a dynamic approach for conforming the customers' satisfactions as its major goal. For different input parameters and various policy scenarios of the model, different predictions of system behaviour would be produced. Therefore, an enterprise can apply the forecasting behaviour to adjust its future input data or policy scenarios of SD model for conforming the company goal or customers' satisfactions. This study conducts a behaviour prediction and sensitivity analysis of different policy scenarios for delivery-oriented production plan, and the optimal policy is suggested. A system dynamics (SD) model is constructed to conduct the staged improvement of delivery-oriented production plan to satisfy the customers' necessities, and thus pursuing the better profit and reputation. The simulation results of the proposed SD model can provide the references of adjusting the future production environment to meet such a complicate and fast changing industry environment. 


\section{MODEL DEVELOPMENT}

System Dynamics (SD) model is provided to conduct the simulation of delivery-oriented production, and its input parameter is from the customer necessity. The Vensims software is applied to develop the above-mentioned SD model. The customer necessity means the order contract which includes the order quantity, delivery request and delivery time. Based on this situation, this model considers the order quantity, the requested delivery date and quantity for each order. Thus, the customer demand and the delivery request are provided in the SD model as the input functions. The time delay is considered among customer demand, order quantity and material demand as well as considers the time delay between order quantity and production demand, and the time delay between material demand and inventory in the proposed model. The proposed system dynamics model is divided into 3 subsystems, income/cost, order/production, and human resource.

In income/cost subsystem (Fig. $1 \mathrm{a}$ ), the delivery quantity (stock quantity) would directly affect the shortage of delivery request. In practical, the more shortage quantity would catch the higher shortage (penalty) cost per unit product. It means that the shortage cost per unit product is an increasing function of the shortage quantity, and such a practical situation is considered in the proposed SD model. In addition, the delivery (transportation) cost per unit product is considered as a decreasing function of delivery quantity, and holding cost is calculated by the unit product price multiple the holding cost ratios. The total cost includes fixed cost, human resource cost, delivery (transportation) cost, holding cost, shortage (penalty) cost, and the production cost. The income only presents the amount revenues of selling the delivery quantity.

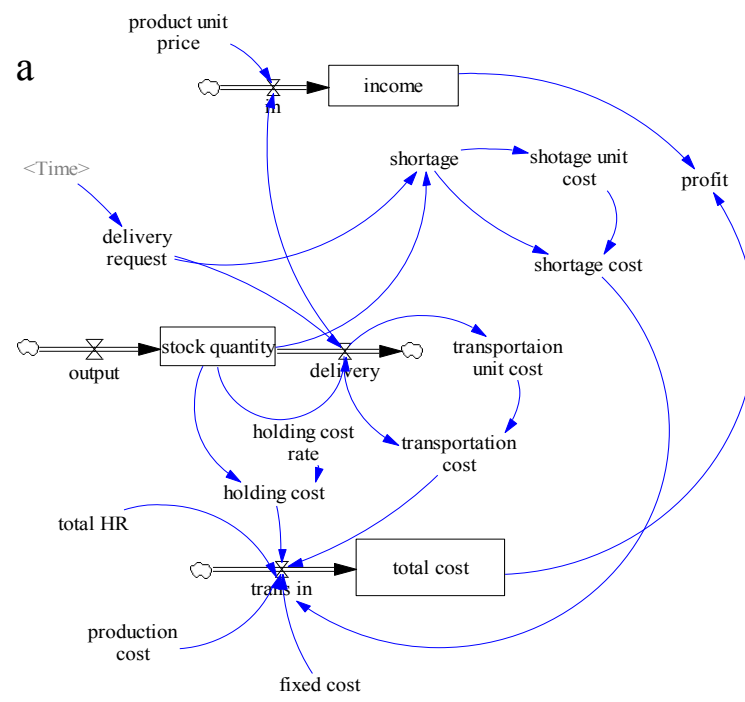

$\mathrm{b}$
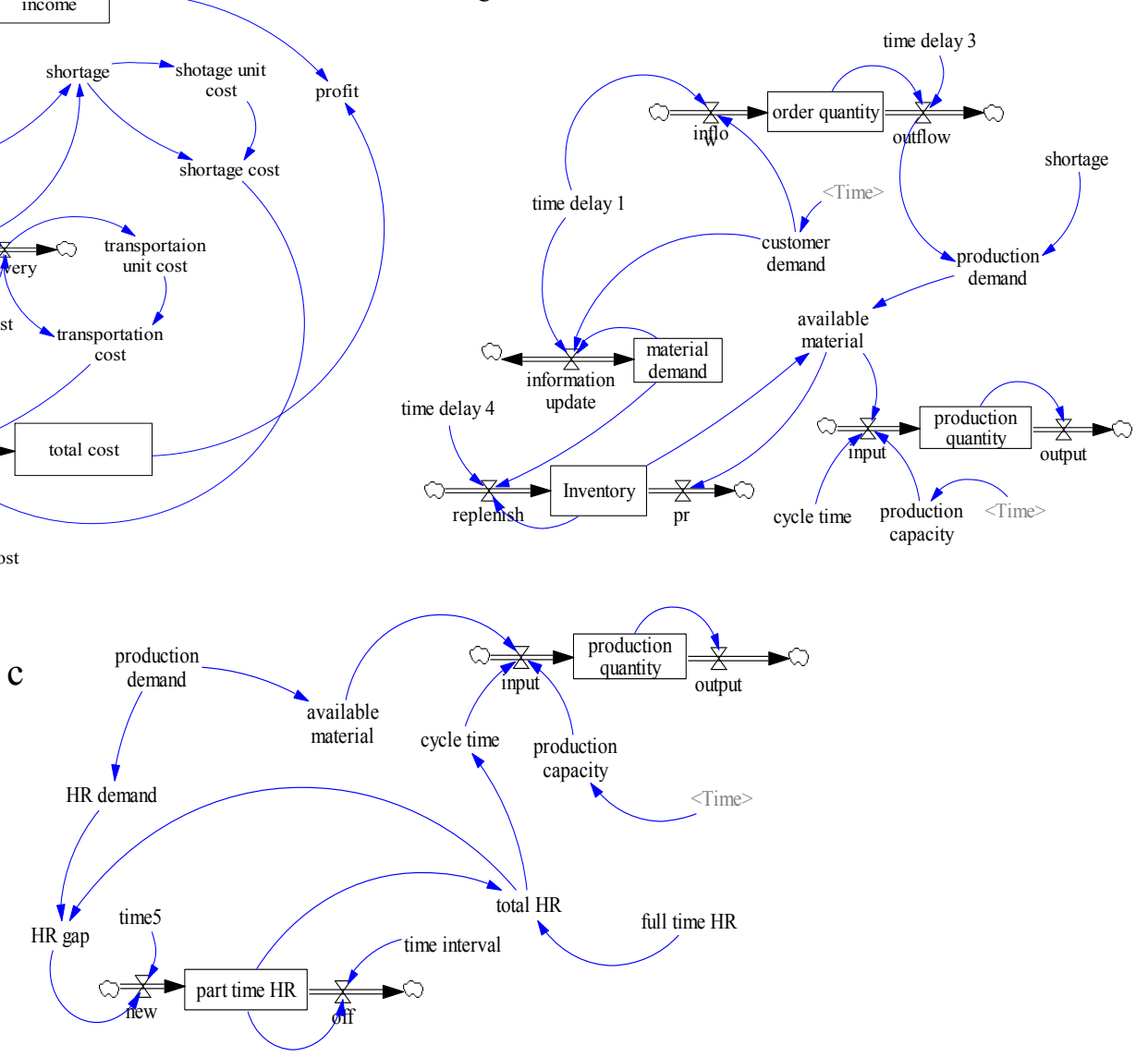

Figure 1: a) Income/Cost, b) order/production, c) human resource. 
In order/production subsystem (Fig. 1 b), order quantity and shortage quantity would affect the production demand, the material inventory and production demand would affect the available materials, and it depends on which one is less. In addition, the available materials, production capacity, and the cycle time could directly constrain the production quantity. The production capacity is practically estimated by the enterprise in every time interval, however, an enterprise can adjust its production capacity if it needs. This subsystem considers the order/production perspective, the time delay among customer demand, order quantity, and material demand is discussed, and the time delay between material demand and inventory is also proposed. The changes of replenishment policy affecting production quantity are revealed in this system because inventory will influence the available material, and available material would affect the production quantity. Besides, that the production quantity constrained by production capacity is also presented in the subsystem. As we know that production quantity would influence the delivery quantity, and the delivery quantity would directly affect the shortage parts. Based on the above-mentioned viewpoints, a better inventory policy and production capacity might reduce the penalty cost of shortage products.

In human resource subsystem (Fig. $1 \mathrm{c}$ ), two parts of human resource, full-time and part-time, are discussed. This subsystem also considers that the more input of human resource would speed up the production rate. Such a phenomenon is provided in the relationship between the production cycle time and total human resource. The more total human resource catches the less cycle time, and the less cycle time could bring the more production rate. In addition, this subsystem also considers that the more production demand leads to the more human resource. Practically, the production demand depends on the order, and more orders need more human resource. However, the part-time human resource is always adopted because it could decrease the cost pressure of human resource for an enterprise, and thus, this model is constructed under such a concept. The human resource (HR) subsystem (Fig. 1 c) shows that production demand would affect the HR demand. The gap between HR demand and full-time HR would be the consideration of recruiting part-time HR. This work also tries to reveals the better human resource policy to satisfy the changes of various production environments. Integrate the above-mentioned three subsystems, the SD model is revealed in Fig. 2. The input functions, customer demand and delivery request (shown in Fig. 3), are provided as a case example for simulation.

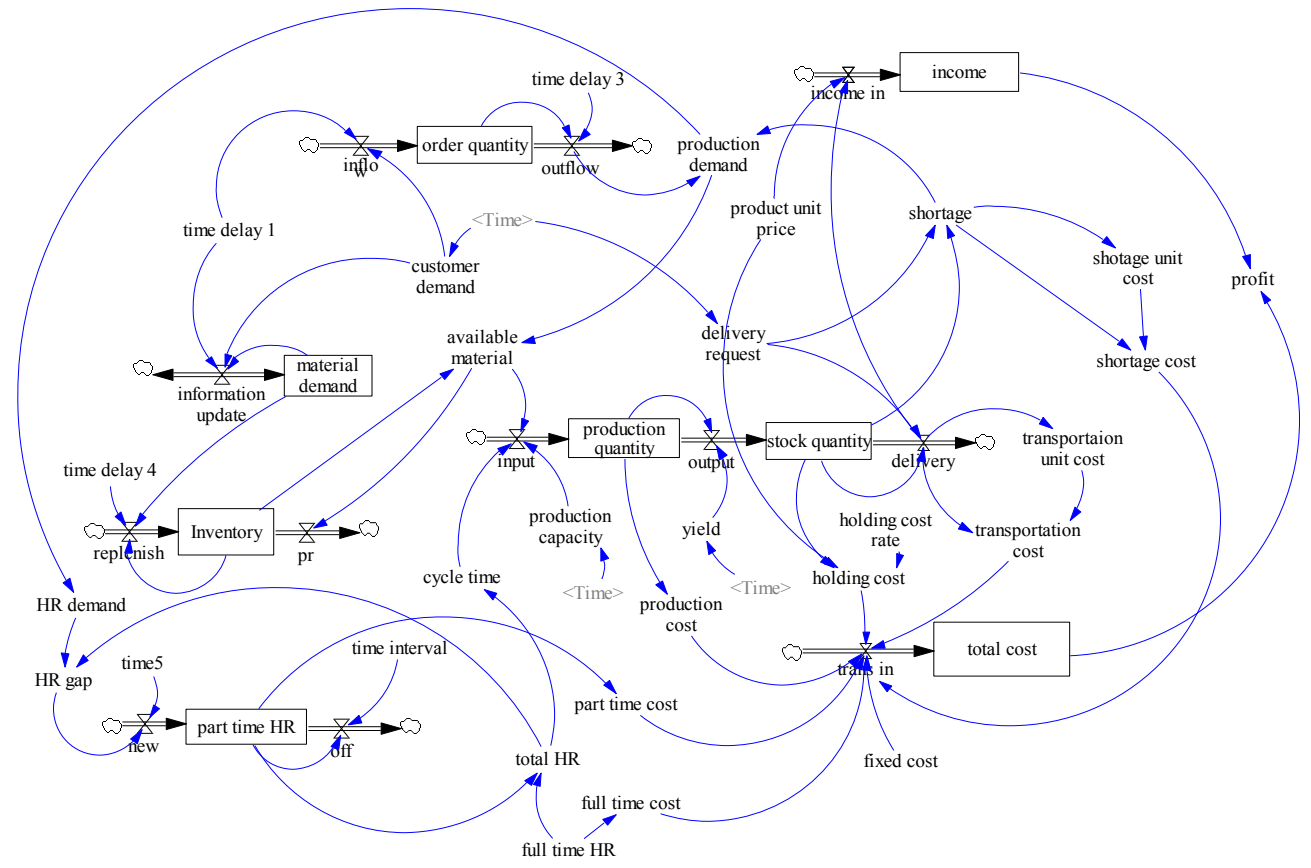

Figure 2: SD model. 


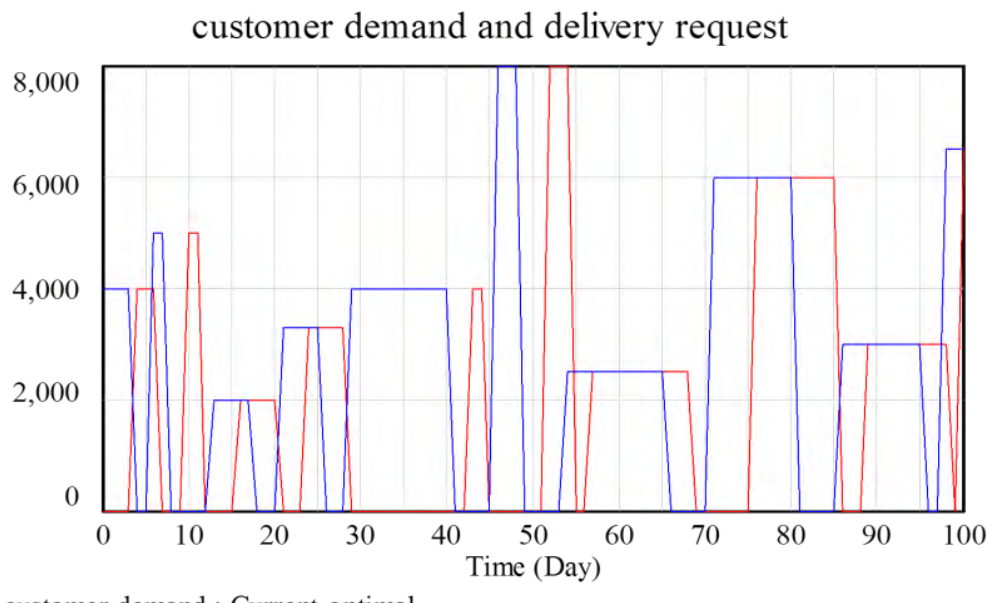

customer demand : Current-optimal

delivery request : Current-optimal

Figure 3: The input functions.

\section{RESULTS AND SENSITIVITY ANALYSIS}

In the exemplified case, the replenishment policy of materials from the material demand to the inventory is to replenish the gap plus 2000 units if the material demand is greater than the inventory, and the affection of time delay is concerned. Besides, if the material demand is lower than the inventory, the policy is to replenish 2000 units only. The production capacity is set as 10,000 minutes per day. Applying these policies conducts the proposed SD model to simulate the make-to-order production. Fig. 4 a reveals that there exists a great gap between delivery request and delivery quantity for the proposed situation. In addition, the similar phenomena (a great amount of shortage) can be found in Fig. 4 b.

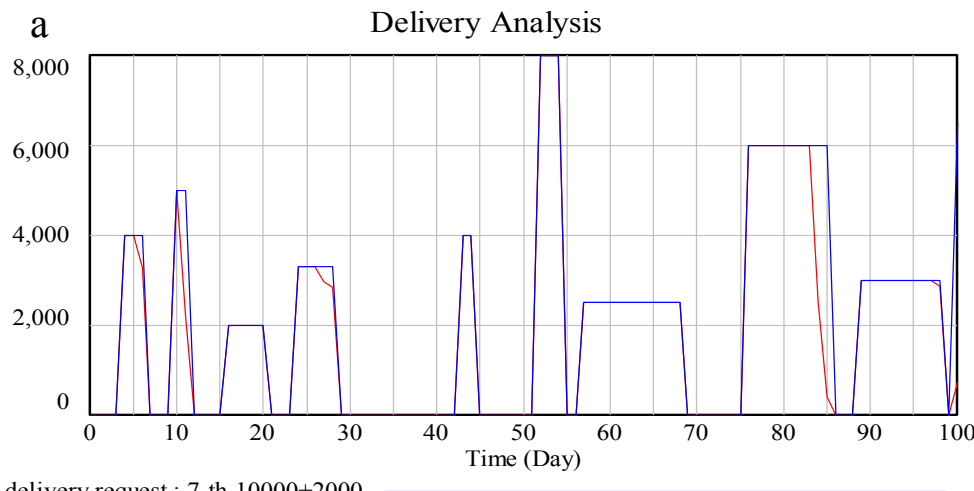

delivery request : 7 -th- $10000+2000$ delivery : 7 -th- $10000+2000$

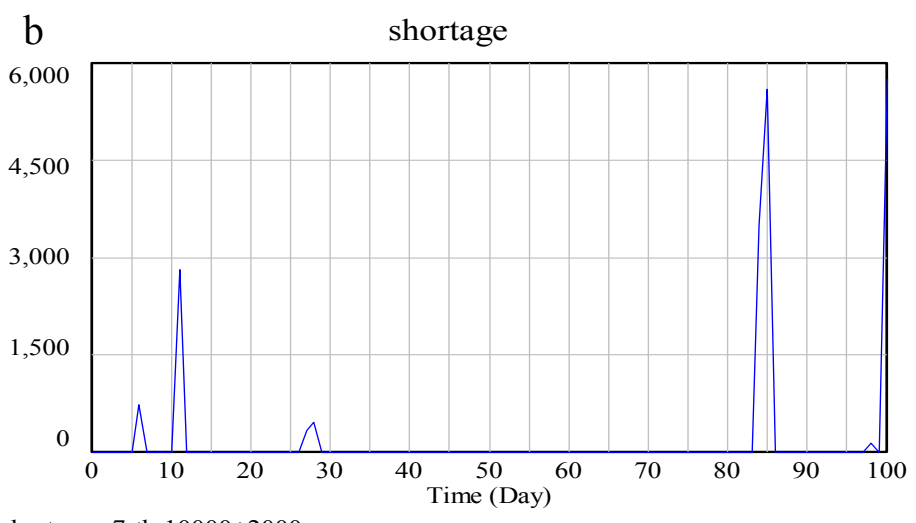

Figure 4: a) The delivery analysis, b) the shortage of exemplified case. 
To improve the above-mentioned gap of delivery quantity, increment of production capacity is a good selection. The production capacity enhance could increase the production/delivery quantity, and thus the shortage quantity could be reduced. Table I presents the shortage condition through the increment of production capacity from 7,000 to 25,000 minutes. The simulation result seems upset because shortage quantity does not have a significant improvement while the production capacity is over 24,000 minutes. However, the simulated result finds that the shortage amount decreases to 2,969 units when the production capacity increases to 24,000 . That is, the shortage rate is down to $1.43 \%$ (shown in Table I). In addition, there is no improvement of shortage if the production capacity is over 24,000 minutes. It reveals that no shortage is hard to achieve by the adoption of production capacity enhance only.

In Table I, the production capacity would increase at least up to 21,000 if the shortage rate of an enterprise should be controlled below $2 \%$. Table I also shows that an optimal profit is around 5,724,220 dollars, but the shortage rate is $3.53 \%$ (over $2 \%$ ) under such a situation. It shows that reaching optimal profit would endure a higher shortage rate. Besides, a higher shortage would make an enterprise catch its bad reputation. In addition, the shadow prices of changing production capacity are presented. The more production capacity (pc) increases, the less shadow price catches. On the other hand, the more production capacity reduces, the more loss of profit (negative shadow price) happens (shown in Table I).

The shortage cannot be eliminated by adopting production capacity enhance only, so the replenishment policy of material inventory might be considered as another key role for shortage improvement. The production capacity is set as 21,000 minutes, and the sensitivity analysis of various replenishment policies of materials is conducted in Table II.

Table I: The sensitivity analysis of various production capacity (replenish policy $=2,000$ ).

\begin{tabular}{|c|c|c|c|c|}
\hline $\begin{array}{c}\text { Production } \\
\text { capacity }\end{array}$ & Shortage & Shortage rate & Profit & Shadow price \\
\hline 25000 & 2969 & $1.43 \%$ & 5671240 & 39.20 \\
\hline 24000 & 2969 & $1.43 \%$ & 5671240 & 42.00 \\
\hline 23000 & 3115 & $1.50 \%$ & 5673020 & 45.36 \\
\hline 22000 & 3416 & $1.65 \%$ & 5676700 & 49.45 \\
\hline 21000 & 3778 & $1.82 \%$ & 5681130 & 54.35 \\
\hline 20000 & 4364 & $2.11 \%$ & 5688310 & 60.50 \\
\hline 19000 & 4951 & $2.39 \%$ & 5695490 & 68.02 \\
\hline 18000 & 5538 & $2.68 \%$ & 5702670 & 77.42 \\
\hline 17000 & 6125 & $2.96 \%$ & 5709860 & 89.51 \\
\hline 16000 & 6712 & $3.24 \%$ & 5717040 & 105.62 \\
\hline 15000 & 7298 & $3.53 \%$ & 5724220 & 128.18 \\
\hline 14000 & 7605 & $3.67 \%$ & 5712930 & 157.41 \\
\hline 13000 & 7962 & $3.85 \%$ & 5698710 & 205.14 \\
\hline 12000 & 9480 & $4.58 \%$ & 5642370 & 279.54 \\
\hline 11000 & 13346 & $6.45 \%$ & 5412690 & 329.39 \\
\hline 10000 & 19320 & $9.33 \%$ & 5083300 & --- \\
\hline 9000 & 25270 & $12.21 \%$ & 4769510 & -313.79 \\
\hline 8000 & 33372 & $16.12 \%$ & 4397770 & -342.77 \\
\hline 7000 & 42366 & $20.47 \%$ & 3962980 & -373.44 \\
\hline
\end{tabular}

Table II: The sensitivity analysis of various replenishment policy (production capacity $=21,000$ ).

\begin{tabular}{|c|c|c|c|c|c|c|c|c|c|c|c|}
\hline $\begin{array}{c}\text { Replenishment } \\
\text { policy }\end{array}$ & 3500 & 3000 & 2500 & 2000 & 1500 & 1000 & 800 & 600 & 400 & 200 & 0 \\
\hline $\begin{array}{c}\text { Shortage } \\
\text { amount }\end{array}$ & 983 & 983 & 983 & 3778 & 26571 & 52657 & 61675 & 72258 & 82410 & 92526 & 101710 \\
\hline Shortage rate & $0.47 \%$ & $0.47 \%$ & $0.47 \%$ & $1.82 \%$ & $12.84 \%$ & $25.44 \%$ & $29.79 \%$ & $34.91 \%$ & $39.81 \%$ & $44.70 \%$ & $49.14 \%$ \\
\hline Profit & 5487622 & 5487622 & 5487622 & 5681128 & 4682040 & 3433014 & 3040848 & 2504950 & 2038652 & 1582679 & 1136435 \\
\hline
\end{tabular}


The original adopting replenishment policy of material inventory is to replenish the gap while the material demand is greater than the material inventory, and no replenishment is conducted if the material demand is lower than the inventory (replenishment policy " 0 " in Table II). The shortage amount, shortage rate, and profit of replenishment policy " 0 " are $101,710,49.14 \%$, and 1,136,435, respectively. It would search some changes for making the shortage rate decreasing because the shortage rate is so high under this policy. Firstly, the sensitivity analysis of this study tries to increase 200 units per iteration to replenish the gap plus 200 while the material demand is greater than the material inventory, and replenishment 200 is conducted if the material demand is lower than the inventory; and then increases the steps to 500 units per iteration. The critical point " 2500 units" is obtained because the more units added would not catch the shortage less (shown in Table II). At this moment, the shortage is 983 units during the simulation period, and the shortage rate reduces to $0.47 \%$.

The entire delivery request is 207,000 units during the simulation period in the exemplified case. In the replenishment policy " 0 ", the whole delivery quantity is only 105,290 units (shortage $=101,710$ ) due to the lack of material inventory (table II). Adopting the replenishment policy " 2500 ", the delivery analysis is conducted as below. The delivery request is 207,000 units during the simulation period, and the simulated delivery quantity is up to 206,062 units (shortage $=983$ ). For initial policy "0", the completion rate of delivery request is only $50.86 \%$, and then adopting the replenishment policy " 2500 ", the completion rate quickly increases to $99.53 \%$ because shortage rate is $0.47 \%$ shown in Table II. In addition, the delivery analysis is shown in Fig. $5 \mathrm{a}$. It is revealed that the delivery fits the delivery request in the most time excluding time 24 to time 28 . In addition, production is a continuous accumulated process to satisfy the requested delivery quantity in a specific time, and such a phenomenon is shown in Fig. 5 b.

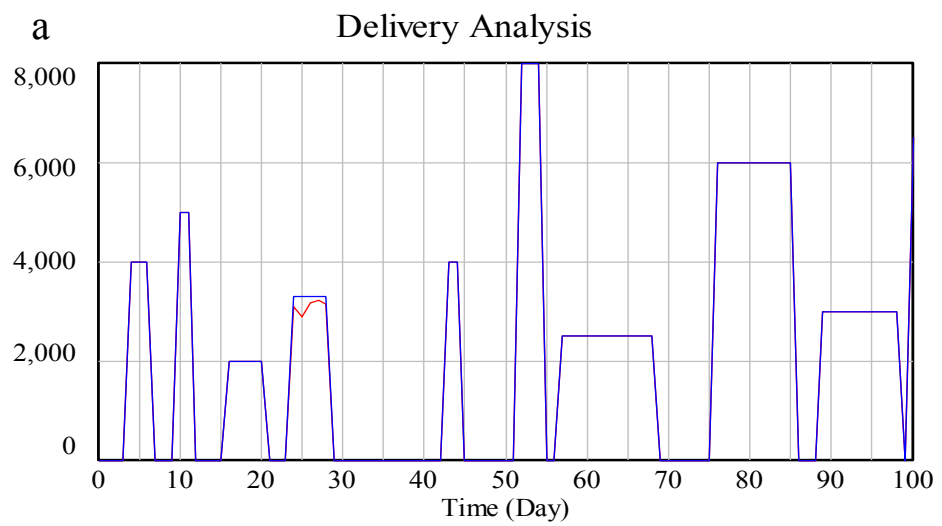

delivery request : $21000+2500$ delivery : $21000+2500$

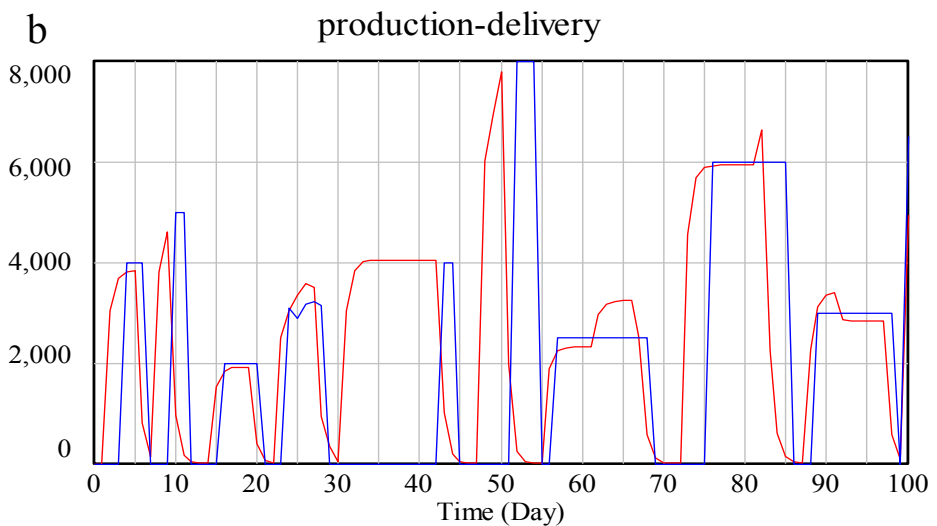

delivery : $21000+2500$

production quantity : $21000+2500$

Figure 5: a) The delivery analysis, b) the production-delivery analysis. 
Table III: The sensitivity analysis of various time-delays $\left(t_{1}, t_{3}, t_{4}\right.$ means time-delay $1,3,4$, respectively).

\begin{tabular}{|c|c|c|c|c|c|c|c|}
\hline Time/shortage & $t_{1}-1.06$ & $t_{1}-1.07$ & $t_{1}-1.08$ & $t_{1}-1.09$ & $t_{3}-1.00$ & $t_{4}-1.00$ & Original \\
\hline 22 & 0 & 0 & 0 & 0 & 0 & 0 & 0 \\
\hline 23 & 0 & 0 & 0 & 0 & 0 & 0 & 0 \\
\hline 24 & 0 & 0 & 0 & 0 & 0 & 0 & 198 \\
\hline 25 & 0 & 0 & 0 & 260 & 30 & 326 & 410 \\
\hline 26 & 0 & 0 & 168 & 291 & 300 & 304 & 130 \\
\hline 27 & 0 & 159 & 408 & 201 & 431 & 165 & 83 \\
\hline 28 & 0 & 233 & 110 & 4 & 43 & 13 & 161 \\
\hline 29 & 0 & 0 & 0 & 0 & 0 & 0 & 0 \\
\hline 30 & 0 & 0 & 0 & 0 & 0 & 0 & 0 \\
\hline Shortage amount & 0 & 392 & 686 & 756 & 804 & 808 & 982 \\
\hline Improvement rate & 1.0000 & 0.6008 & 0.3014 & 0.2301 & 0.1813 & 0.1772 & - \\
\hline
\end{tabular}

The shortage of 982 units is shown in the following Table III. These shortages are gathered from time 24 to time 28. The production capacity and replenishment policy are enhanced, but there still exists 982 shortages left. At this time, this work tries to investigate the affection of time-delay. There are three major time-delays selected to be investigated; they are time-delay 1, 3, and 4 because they are influenced material demand, production demand, and inventory, respectively. This work tries to reduce the time-delay 1,3 , and 4 separately in order to find out which one is the critical factor. Firstly, set time-delay 4 to be no delay and others keep unchanging; unfortunately, it merely catches the $17.72 \%$ improvement (from 982 to 808 ). Secondly, set time-delay 3 to be no delay and others remain constant, it only reaches the $18.13 \%$ improvement (from 982 to 804). Last, time-delay 1 is discussed. This work reduces the time-delay 1 from 1.1 to 1.07 , and then a significant improvement is revealed $(60.08 \%)$. Furthermore, this paper tries to reduce time-delay 1 to be 1.06 , and a complete improvement $(100 \%)$ is achieved (shown in table III). It is easily to understand that the time-delay 1 would play a key role in the delivery-oriented production plan because it affects the material demand directly.

This paper further goes to discuss the human resource (HR), whenever the replenishment policy and production capacity enhance are applied, the part time HR seems remaining in lower level. It is no longer strongly tending for reducing the cycle time of production to increase the production rate because of the increment of production capacity (shown in Figs. 6 and 7). The simulation result also reveals that the adoption of more replenishment of material inventory and the enhance of production capacity would make the necessity of part time HR keep in the lower level during most part of simulation period. Actually, adopting both of two policies, the part-time HR could stay in the lowest level, and thus, the HR cost could be minimization.

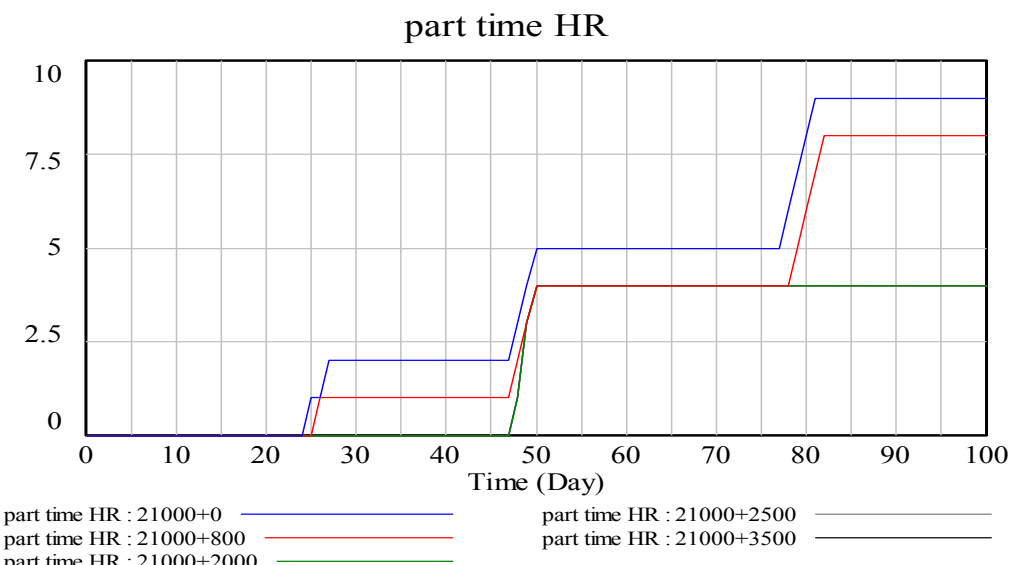

part time HR : $21000+2000$

Figure 6: Part-time HR between original and adopted two policies. 


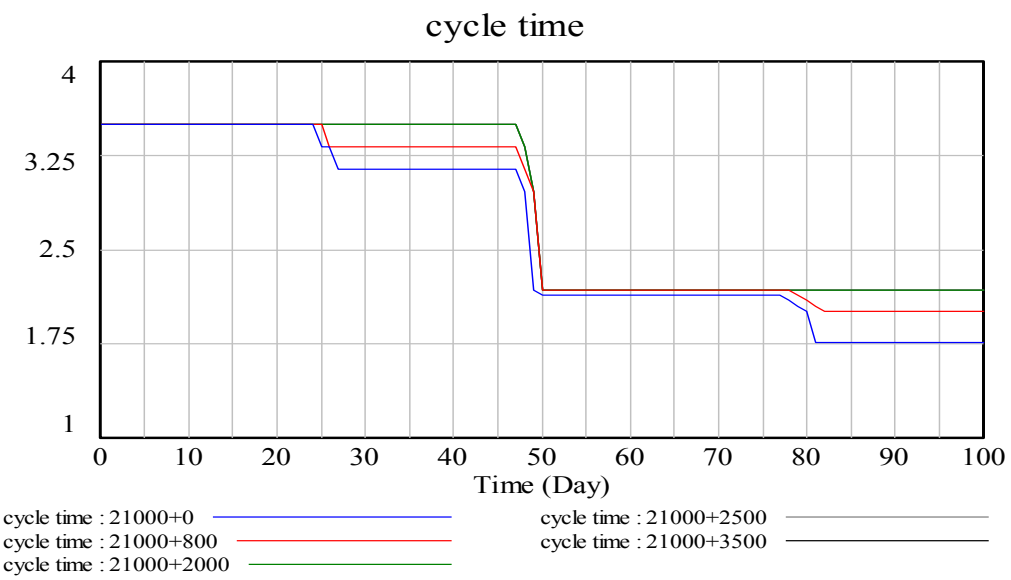

Figure 7: Cycle time between original and adopted two policies.

\section{CONCLUSIONS}

Though an approach to adjusting enterprise's policy dynamically for conforming customers' satisfactions is a practical problem, it lacks discussions. This work is aimed to construct a dynamic approach to conform the customers' satisfactions. Therefore, an approach "A staged improvement simulation" is conducted to complete the goal of delivery-oriented production plan.

The main contributions of this study are listed as follows. This work applies SD model to predict the shortage situation under the selections of various policies. It could provide a fast-change system behaviour through the changes of the input data or policies. In addition, the simulation results of SD model can provide a referenced production schedule under the given situations of production capacity, human resource, replenishment policy, time delay affection and so on. Moreover, SD model can quick calculate the performance improvement after adopted various policies, and then the most important key factor can be found. The sensitivity analysis is conducted to suggest optimal production capacity and replenishment material policy. Furthermore, SD model can quickly response the changes of system behaviour, and such a characteristic would make an enterprise have enough time to cope with unpredictable economic environment. In sum, this study would function as a valuable decision support tool because of the application of computer packaged software. That is, other enterprises can duplicate this study to solve their problems by changing input functions and policies.

The future focal researches are recommended to develop a mathematical model to deal with the situations of the layout of production lines according to the simulated production quantity in every production time interval. Besides, the abrupt change of production capacity and abrupt insert new orders are suggested for future investigations and discussions. A subsystem of product quality would be also highly recommended to develop. In summary, this study can offer a good and valuable tool to deal with performance improvement of delivery-oriented production plan for an enterprise.

\section{ACKNOWLEDGEMENT}

The author would like to thank the anonymous referees who kindly provided the comments to improve and complete this paper.

\section{REFERENCES}

[1] Ackoff, R. L. (2010). Systems thinking for curious managers, Triarchy Press, Axminster 
[2] Bateson, G. (1979). Mind and nature: A necessary unity (Advances in systems theory, complexity, and the human sciences), Hampton Press, New York

[3] Bernhard, T. (1993). Systems engineering: Principles and practice of computer-based systems engineering, John Wiley \& Sons, Chichester

[4] Capra, F. (1997). The web of life - A new scientific understanding of living systems, Anchor Books, New York

[5] Dangerfield, B. C. (1999). System dynamics applications to European health care issues, Journal of the Operational Research Society, Vol. 50, No. 4, 345-353, doi:10.2307/3010452

[6] Gharajedaghi, J. (2005). Systems thinking: Managing chaos and complexity - A platform for designing business architecture, Butterworth-Heinemann, Burlington

[7] Haines, S. G. (2000). The systems thinking approach to strategic planning and management, St. Lucie Press (CRC Press), Boca Raton, doi:10.1201/9781420025699

[8] Warren, K. (2002). Competitive strategy dynamics, John Wiley \& Sons, Chichester

[9] Schiuma, G.; Carlucci, D.; Sole, F. (2012). Applying a systems thinking framework to assess knowledge assets dynamics for business performance improvement, Expert Systems with Applications, Vol. 39, No. 9, 8044-8050, doi:10.1016/j.eswa.2012.01.139

[10] Yim, N.-H.; Kim, S.-H.; Kim, H.-W.; Kwahk, K.-Y. (2004). Knowledge based decision making on higher level strategic concerns: system dynamics approach, Expert Systems with Applications, Vol. 27, No. 1, 143-158, doi:10.1016/j.eswa.2003.12.019

[11] Larsen, E. R.; van Ackere, A.; Warren, K. (1997). The growth of service and the service of growth: Using system dynamics to understand service quality and capital allocation, Decision Support Systems, Vol. 19, No. 4, 271-287, doi:10.1016/S0167-9236(96)00065-6

[12] Quaddus, M.; Intrapairot, A. (2001). Management policies and the diffusion of data warehouse: a case study using system dynamics-based decision support system, Decision Support Systems, Vol. 31, No. 2, 223-240, doi:10.1016/S0167-9236(00)00133-0

[13] Dyner, I.; Smith, R. A., Pena, G. E. (1995). System dynamics modelling for residential energy efficiency analysis and management, Journal of the Operational Research Society, Vol. 46, No. 10, 1163-1173, doi:10.1057/jors.1995.165

[14] Lei, X.; Zhang, J.; Li, J. (2012). A system dynamics model for urban low-carbon transport and simulation in the city of Shanghai, China, Advances in Information Sciences and Service Sciences, Vol. 4, No. 1, 239-246, doi:10.4156/aiss.vol4.issue1.31

[15] Li, J.; Lin, Y.; Jin, F. (2012). A supply chain simulation model with customer's satisfaction, International Journal of Advancements in Computing Technology, Vol. 4, No. 10, 125-132, doi:10.4156/ijact.vol4.issue10.15

[16] Rodrigues, A. G.; Williams, T. M. (1998). System dynamics in project management: assessing the impacts of client behaviour on project performance, Journal of the Operational Research Society, Vol. 49, No. 1, 2-15. doi:10.1057/palgrave.jors.2600490

[17] Zhao, X.; Yang, Y.; Liu, A.; Hu, J.; Jia, J. (2012). System dynamic modeling of owners' influences on the outcome of mega-projects: a case study from China, Journal of Convergence Information Technology, Vol. 7, No. 3, 91-100, doi:10.4156/jcit.vol7.issue3.11

[18] Tako, A. A.; Robinson, S. (2012). The application of discrete event simulation and system dynamics in the logistics and supply chain context, Decision Support Systems, Vol. 52, No. 4, 802-815, doi:10.1016/j.dss.2011.11.015

[19] Suryani, E.; Chou, S.-Y.; Chen, C.-H. (2010). Air passenger demand forecasting and passenger terminal capacity expansion: A system dynamics framework, Expert Systems with Applications, Vol. 37, No. 3, 2324-2339, doi:10.1016/j.eswa.2009.07.041

[20] Suryani, E.; Chou, S.-Y.; Hartono, R.; Chen, C.-H. (2010). Demand scenario analysis and planned capacity expansion: A system dynamics framework, Simulation Modelling Practice and Theory, Vol. 18, No. 6, 732-751, doi:10.1016/j.simpat.2010.01.013

[21] Lyneis, J. M. (2000). System dynamics for market forecasting and structural analysis, System Dynamics Review, Vol. 16, No. 1, 3-25, doi:10.1002/(SICI)1099-1727(200021)16:1<3::AIDSDR183>3.0.CO;2-5

[22] Li, C.; Zhou, L.; Li, N.; Zeng, M. (2012). Modelling and simulation of power grid engineering project based on system dynamics on the background of smart grid, Systems Engineering Procedia, Vol. 3, 92-99, doi:10.1016/j.sepro.2011.11.013 
[23] Xu, J.; Li, X. (2011). Using system dynamics for simulation and optimization of one coal industry system under fuzzy environment, Expert Systems with Applications, Vol. 38, No. 9, 11552-11559, doi:10.1016/j.eswa.2011.03.033

[24] Wang, Y.-C.; Cheng, W.-T. (2008). A sensitivity analysis of solving joint replenishment problems using the RAND method under inaccurate holding cost estimates and demand forecasts, Computers \& Industrial Engineering, Vol. 55, No. 1, 243-252, doi:10.1016/j.cie.2007.12.010

[25] Ayomoh, M. K. O.; Oladeji, O.; Oke, S. A. (2004). Investing the dynamics of an inventory system in the manufacturing sector: a case study, South African Journal of Industrial Engineering, Vol. 15, No. 1, 19-30, doi: 10.7166/15-1-235

[26] Berling, P. (2008). Holding cost determination: An activity-based cost approach, International Journal of Production Economics, Vol. 112, No. 2, 829-840, doi:10.1016/j.ijpe.2005.10.010

[27] Estevez-Fernandez, A. (2012). A game theoretical approach to sharing penalties and rewards in projects, European Journal of Operational Research, Vol. 216, No. 3, 647-657, doi:10.1016/j.ejor.2011.08.015

[28] Kosuch, S.; Lisser, A. (2010). Stochastic shortest path problem with delay excess penalty, Electronic Notes in Discrete Mathematics, Vol. 36, 511-518, doi:10.1016/j.endm.2010.05.065

[29] Liu, L.; Li, Y. (2006). The fuzzy quadratic assignment problem with penalty: New models and genetic algorithm, Applied Mathematics and Computation, Vol. 174, No. 2, 1229-1244, doi:10.1016/j.amc.2005.06.012

[30] Benson, R. F.; Cunningham, S. P.; Leachman, R. C. (1995). Benchmarking manufacturing performance in semiconductor industry, Production and Operations Management, Vol. 4, No. 3, 201-216, doi:10.1111/j.1937-5956.1995.tb00052.x

[31] Gering, M. (1999). Activity based costing and performance improvement, Management Accounting, Vol. 77, No. 3, 24-25

[32] Kane, V. E. (1986). Process capability indices, Journal of Quality Technology, Vol. 18, No. 1, 41-52

[33] Meyersdorf, D.; Yang, T. (1997). Cycle time reduction for semiconductor wafer fabrication facilities, Advanced Semiconductor Manufacturing Conference and Workshop, IEEE/SEMI, 418-423, doi:10.1109/ASMC.1997.630772

[34] Ohta, H.; Nakatani, T. (2006). A heuristic job-shop scheduling algorithm to minimize the total holding cost of completed and in-process products subject to no tardy jobs, International Journal of Production Economics, Vol. 101, No. 1, 19-29, doi:10.1016/j.ijpe.2005.05.004

[35] Raja, S. S.; Vasuki, S. (2012). Performance analysis of screening diabetic retinopathy, Journal of Scientific \& Industrial Research, Vol. 71, No. 12, 804-809

[36] Cannon, A. R. (2008). Inventory improvement and financial performance, International Journal of Production Economics, Vol. 115, No. 2, 581-593, doi:10.1016/j.ijpe.2008.07.006

[37] Xu, J. (2012). Rule-based automatic software performance diagnosis and improvement, Performance Evaluation, Vol. 69, No. 11, 525-550, doi:10.1016/j.peva.2009.11.003

[38] Aburas, H. M. (2010). An integrated performance management framework for a multi-business company, South African Journal of Industrial Engineering, Vol. 21, No. 1, 35-43, doi: $\underline{10.7166 / 21-1-64}$ 